\title{
Um olhar demográfico sobre a constituição da macrometrópole paulista: fluxos populacionais, integração e complementaridade*
}

\author{
A demographic perspective on the constitution of the São Paulo \\ macrometropolis: population flows, integration and complementarity
}

Késia Anastacio Alves da Silva José Marcos Pinto da Cunha Guilherme Margarido Ortega

\section{Resumo}

Este estudo tem por objetivo analisar a formação de novas morfologias urbanas a partir do olhar demográfico que passa, não apenas pela formação dos vetores de expansão da população, mas também e, principalmente, pelos fluxos populacionais, sejam eles motivados por mudança de residência ou mesmo para o desenvolvimento de atividades cotidianas. Busca, também, contribuir para o debate sobre a constituição de uma nova forma urbana, a macrometrópole paulista, que ainda carece de melhor e mais ampla discussão e delimitações teóricas e empíricas. De maneira resumida, busca-se mostrar que essa nova forma urbana tem uma clara contrapartida no processo de redistribuição espacial e mobilidade da população.

Palavras-chave: mobilidade espacial da população; metropolização; cidade-região; migração; mobilidade pendular.

\begin{abstract}
The objective of this study is to analyze the formation of new urban morphologies from the demographic perspective, which approaches not only the formation of vectors of population expansion, but also, and mainly, population flows, either motivated by a change of residence or caused by the development of daily activities. This article also aims to contribute to the debate about the constitution of a new urban form, the São Paulo Macrometropolis, which still lacks better and broader discussions and theoretical and empirical delimitations. To put it in a nutshell, the aim is to show that this new urban form has a clear counterpart in the process of spatial redistribution and population mobility.
\end{abstract}

Keywords: population's spatial mobility; metropolization; city-region; migration; commuting. 


\section{Introdução}

As pesquisas voltadas para a compreensão do processo de metropolização e constituição das metrópoles no Brasil são inúmeras, bem como são realizadas sob a ótica de diferentes campos do saber, já que entender a formação das metrópoles em sua totalidade constitui um grande desafio. Contudo, tais estudos ajudam a compreender, não somente os condicionantes do processo de metropolização, mas sobretudo suas consequências segundo várias dimensões, tais como: econômica, social, política e demográfica. É exatamente sobre esta última dimensão que o presente artigo se debruça.

No final do século $X X$, observou-se que algumas metrópoles passaram a apresentar mudanças em sua morfologia. Agora, elas são caracterizadas não apenas pela concentração, ou seja, não possuem mais uma forma compacta, mas são estereotipadas por uma desmedida extensão territorial, dispersão e fragmentação da mancha urbana, além de aglutinarem municípios de diversos tamanhos e funcionalidades e outras aglomerações urbanas. Essa constatação leva à reflexão sobre a validade de noções tradicionais (como de centro-periferia, desconcentração, entre outras) que até então eram utilizadas e que pareciam refletir a forma como se estruturavam grandes aglomerações e assentamentos humanos observados. Destaca-se que as profundas alterações na estrutura metropolitana do período fordista não ocorreram apenas nas metrópoles brasileiras, mas foram observadas em outras metrópoles ao redor do mundo. Tal fato levou diversos autores a criarem novas nomenclaturas para a morfologia urbana que estava emergindo, tais como: cidade-região (Scott, 2001), cidade global (Sassen, 2001), exópole (Soja, 1994), cidade difusa (Indovina, 1990), edgecity (Garreau, 1991), Metápole (Ascher, 1998) entre outros. Pode-se dizer que no bojo dessa discussão surge o debate em torno da chamada "macrometrópole paulista", territorialização proposta pela Emplasa (Empresa Paulista de Planejamento Metropolitano S.A.). Muito embora essa questão já havia sido prenunciada por Souza (1978, apud Santos, 2005) no final dos anos 1970, não há dúvidas de que apenas mais recentemente 0 tema tenha ganho preeminência e passe a ser motivo de estudos. ${ }^{1}$

De fato, o fenômeno que se observa na atualidade precisa de mais estudos e compreensão para apreender, não apenas sua dimensão territorial, mas também como será sua evolução. Porém, parece não haver dúvidas de que o que se observa hoje ainda é um prenúncio ou início desse processo que, portanto, precisa ser melhor compreendido e conceituado. Essa questão se coloca como um grande desafio (e também oportunidade) para todos os gestores e planejadores, como também para os estudiosos do tema.

Assim, embora este artigo não tenha a pretensão de realizar uma discussão ampla sobre a constituição de macrometrópole, já que isso envolveria inúmeras dimensões como as apontadas pela Emplasa (2012), ele se apresenta como uma contribuição para compreensão da constituição dessa nova forma urbana, a partir da perspectiva demográfica, especialmente sob a ótica da mobilidade espacial da população que ocorre no âmbito dessa nova base territorial. Portanto, através dos fluxos materiais, serão apresentadas evidências que sugerem uma relação de complementaridade ${ }^{2}$ 
entre os aglomerados urbanos ${ }^{3}$ que constituem a macrometrópole paulista.

Nesse sentido, o presente artigo, embora ampliado em suas reflexões teóricas, foi motivado por algumas reflexões e análises realizadas em dois estudos mais amplos sobre a macrometrópole paulista (Cunha, 2013 e 2014) e pretende contribuir para esse debate. Assim, com base nos dados dos censos demográficos de 1991, 2000 e 2010, o objetivo deste trabaIho é analisar os reflexos demográficos e as possíveis complementaridades regionais estabelecidas no âmbito dessa nova morfologia, tendo como foco o fenômeno da mobilidade espacial da população.

\section{A constituição de novas formas urbanas}

Desde os estudos de Gottmann $(1961)^{4}$ nos anos de 1960 - apesar de os estudos regionais se esvanecerem com a crise dos anos de 1970 e com o fortalecimento da perspectiva teórica do estruturalismo com ênfase nas lógicas da produção social do espaço urbano e suas externalidades -, muitos pesquisadores debruçaram suas investigações em fenômenos relacionados às transformações nos ambientes metropolitanos e no seu entorno. Porém, cabe enfatizar que nos últimos vinte anos, devido às crises do capitalismo, a chamada reestruturação produtiva e com 0 advento da globalização, as pesquisas que buscavam compreender as transformações socioespaciais no âmbito regional, principalmente na escala metropolitana, efervesceram-se e buscaram (e ainda buscam) compreender as novas lógicas de organização e estruturação das metrópoles.

Nesse sentido, observaram-se importantes mudanças estruturais ao redor do mundo e que estavam relacionadas à ascendência da globalização, à difusão de tecnologias de informação, à crise dos estados-nações e ao regime de acumulação fordista. Essa profunda reestruturação provocou o desmantelamento das economias nacionais, em função da radical liberalização econômica baseada na neutralidade do Estado, que foram seguidas por medidas de desregulamentação econômica, privatização, terceirização e flexibilização de diversas áreas trabalhistas. A adoção dessas medidas de restruturação, aliada à difusão de novas tecnologias de informação e comunicação (NTIC), incorporou progressivamente os países ditos em desenvolvimento à dinâmica globalizada à nova fase de acumulação do capital, nomeada por Harvey (1992) como flexível.

Destaca-se que, em tempos de globalização e reestruturação produtiva, o capital preferencialmente se reproduz em escalas territoriais distintas do período fordista, o que contribui para a estruturação de novos "arranjos espaciais" (Harvey, 2013). Assim, se as mudanças contemporâneas no processo de metropolização acompanharam as transmutações da reprodução do capital e suas crises cíclicas, os movimentos populacionais nesses ambientes também apresentaram características especificas em cada momento da produção da metrópole. Segundo Ascher (1998), essas transformações têm rebatimentos na mobilidade espacial da população, por exemplo: aumento dos movimentos pendulares, bem como nas múltiplas mobilidades das famílias que 
permeiam as mobilidades residenciais, profissionais e do quotidiano, já que as "metamorfoses" no tecido metropolitano tendem a alongar as distâncias percorridas no dia a dia, e também pela colonização de novas áreas rurais e cidades periféricas.

Nesse sentido, tendo em vista a revolução tecnológica e digital que marcou o final do século XX, Sassen (1993) questionou se o desenvolvimento das telecomunicações e a ascendência das indústrias de informação levariam ao declínio da importância do lugar ou das cidades. A autora questiona, ainda, se a proliferação dessas tecnologias evidenciaria todo o ônus das economias de aglomeração e ocasionaria a fuga de escritórios e fábricas das áreas metropolitanas para outras áreas, menos congestionadas e de custo mais baixo. Porém, muitos estudos ${ }^{5}$ sobre o crescimento das aglomerações nos últimos vinte anos demonstraram que a resposta para esse questionamento não é definitiva, mas parcial. No caso dos países desenvolvidos, existe uma dispersão das atividades econômicas, mas também se observam novas formas de centralização territorial.

No cenário brasileiro, a partir dos anos 1990 também foi possível verificar a recuperação do protagonismo, crescimento e expansão de diversas metrópoles, fenômeno este intitulado por Davidovich (2013) como a "volta das metrópoles". Com a volta da importância do papel das metrópoles, ocorreu também a revalorização do solo metropolitano. Devido à profunda reestruturação que circunscreveu essas áreas, a área metropolitana se tornou locus dos centros de decisões e gestão e passou a abrigar os setores produtivos mais dinâmicos da economia. Consequentemente, o espaço metropolitano se tornou residência da parcela mais abastada dos setores sociais.

Há, também, uma reorganização dos setores produtivos no âmbito metropolitano, principalmente os ditos industriais, que avançam em direção ao seu entorno, bem como uma refuncionalização dos seus centros que passam a abrigar na atualidade atividades que se relacionam ao "circuito superior da economia global". ${ }^{6}$ Nas palavras de Lencioni (2011a, 2015) ocorre uma verdadeira metamorfose na produção desses espaços que os ressignifica: rompe-se com a expansão do fato urbano para a expansão do fato metropolitano. Ou seja, o período atual é marcado pela difusão do processo de metropolização do espaço, já que este "se constitui num fenômeno que vai além da dimensão territorial das metrópoles, referindo-se, também, aos modos de vida e de produção" (Firkowski e Moura, 2002, p. 25). Essas metrópoles são caracterizadas por "espaços urbanizados cada vez mais vastos, heterogêneos, descontínuos, formadas, por vezes, por grandes cidades, cada vez menos ligadas a uma economia regional, e cujo interior se transforma em espaços de serviços e lazeres" (Ascher, 1998, p.16).

Constata-se, na atualidade, a produção de uma metrópole "dispersa" que se espraia de maneira intensa, e as novas fronteiras urbanas também entram na lógica do consumo, com objetos espalhados pelo seu tecido, como comércios, cinemas, restaurantes, condomínios fechados, etc. (Lencioni, 2011b). Contudo, cabe salientar que, ainda que ocorra o declínio na densidade populacional das metrópoles, devido à expansão do tecido metropolitano, por vezes, nessa "metamorfose" as antigas áreas centrais da metrópole fordista tendem a 
se densificar ainda mais, bem como são perpassadas por diversas transformações urbanísticas, valorizam-se e passam a abrigar um conjunto de atividades terciárias. É, nessa integração, entre a densificação de certos lugares e o declínio na densidade de outros, que os espaços dos aglomerados tendem a aumentar suas descontinuidades.

Destaca-se que, além do processo de reestruturação produtiva, muitas metrópoles passam pelo processo de dilatação do tecido metropolitano. Contudo, na atualidade, a lógica de expansão do tecido metropolitano não se relaciona mais com o crescimento da densidade demográfica dos grandes centros urbanos, mas está associada ao aumento da migração intrametropolitana, bem como às mudanças demográficas na composição dos domicílios, aliada ao crescimento do consumo de terra per capita. Portanto, o fenômeno de redistribuição espacial da população no âmbito metropolitano contribui para o processo de dilatação e dispersão da área metropolitana, ou seja, mesmo em períodos de baixo crescimento populacional, a expansão da mancha urbana da metrópole permanece, fato demonstrado por Cunha (2015) para a região metropolitana de São Paulo. Ressalta-se que a expansão da mancha metropolitana foi acompanhada, não só pelo aumento dos fluxos migratórios intrametropolitanos, mas também pelo crescimento dos movimentos pendulares. ${ }^{7}$

Portanto, a dispersão urbana para além da área central das áreas metropolitanas refletiu no aumento dos deslocamentos entre casa e trabalho. Outra característica das aglomerações urbanas metamorfoseadas pelo processo de metropolização é que estas se expandem e estreitam suas relações com aglomerações vizinhas a partir da ampliação dos fluxos de pessoas, mercadorias e informações. Nas palavras de Ascher (1998, p. 9), "as metrópoles estão, assim e ao mesmo tempo, mais diluídas e mais compactas mais integradas e mais descontínuas".

Assim, é através da mobilidade espacial da população, que este trabalho analisa a formação de novas morfologias urbanas. Em outras palavras, o trabalho analisa quais são as contrapartidas demográficas com 0 delineamento de novas territorialidades. Nesse sentido, a hipótese que se suscita é que, se a metropolização do espaço imprime novas características aos lugares, também tem reflexo na redistribuição espacial da população e nas características das pessoas.

\section{As metamorfoses da metrópole: a constituição de uma cidade-região no estado de São Paulo}

Como visto anteriormente, a expansão da metropolização e suas relações com a dinâmica global imprimiram novas características aos ambientes metropolitanos e configuraram uma nova morfologia urbana caracterizada pela concentração de aglomerações de dimensões distintas. Contudo, cabe destacar que a formação dessa nova forma urbana é demarcada pela convergência de antigos e novos processos de estruturação do espaço urbano, por exemplo, a expansão centro/periferia, seguida por fluxos populacionais centrípetos, agora convive com a expansão do tecido urbano para além das áreas periféricas, que se diluem ao longo 
dos eixos viários e configuram uma aglomeração difusa e dispersa.

A formação da cidade-região Paulista relaciona-se ao processo de desconcentração industrial iniciado na década de 1970 (Lencioni, 2011a). A difusão do processo de metropolização do espaço pelo tecido urbano de São Paulo - aliada à desconcentração industrial que, primeiramente, se deu em direção ao entorno da região metropolitana de São Paulo (RMSP) e, posteriormente, para as outras regiões metropolitanas e aglomerados situados ao redor desta - contribuiu para a metamorfose metropolitana e a formação de uma nova estrutura urbana. Pontua-se que esse fato reafirmou a primazia da cidade de São Paulo - devido à concentração de atividades relacionadas à gestão do capital nessa cidade. Nesse sentido, observa-se o papel preponderante das redes de circulação no processo de difusão do metropolitano, já que estas possibilitaram a maior circulação dos fluxos materiais e imateriais, ${ }^{8}$ o que gerou maior integração e complementaridade entre diversas aglomerações do estado (ibid.).

Portanto, suscita-se que essas transformações não elucidam apenas um processo de desconcentração demográfica e industrial dos grandes centros metropolitanos em direção às cidades de porte médio e a outras aglomerações urbanas, já que as regiões metropolitanas no Brasil não perderam sua importância e ainda continuam sendo os principais polos de concentração populacional. Contudo, o que se constata em certas áreas metropolitanas é a formação de novas morfologias urbanas constituídas através da expansão do processo de metropolização do espaço.
Nesse sentido, Moura (2009) observa a formação de diversos "arranjos urbano-regionais" pelo País, sendo o mais emblemático deles o "arranjo-urbano-regional de São Paulo", que se estende e se dilui ao longo de um perímetro de aproximadamente $200 \mathrm{~km}$. Ressalta-se que a desmedida extensão territorial desse arranjo e sua característica urbano-regional policêntrica ${ }^{9}$ estão relacionadas a um conjunto de infraestruturas presentes no estado e que permitem um intenso fluxo de pessoas, mercadorias, informações, além de formarem um espaço polinuclear devido à presença de portos, aeroportos e pela aglutinação de distintos centros regionais.

Essa metamorfose, portanto, foi propiciada por conjunto de condições gerais de produção, ${ }^{10}$ tais como o sistema viário datado dos anos de 1920, a presença de um mercado de trabalho qualificado e um conjunto de infraestrutura e polos voltados para ciência e tecnologia, além de outras infraestruturas aqui já citadas como aeroportos, sistemas de suporte à produção e a decisões locacionais, etc. (Diniz e Diniz, 2007). Destaca-se que São Paulo e as regiões metropolitanas próximas a ela, tais como a região metropolitana de Campinas, Santos e a área que circunda o município de São José dos Campos - nesse processo de expansão da metropolização do espaço, reestruturação produtiva e mudanças nas lógicas de reprodução do capital - passaram a se dotar de novas funções no âmbito da economia nacional e internacional, bem como formaram uma nova morfologia urbana que se integrou através de um espaço de fluxos e de compartilhamento do uso do solo e de infraestrutura. 
Para muitos, essa área é conhecida como macrometrópole paulista, termo usado nos meios institucionais para definir o complexo metropolitano expandido localizado no cone leste do estado de São Paulo e que, segundo Cunha et al. (2013), é considerado o sistema de cidades mais importante do País. Composto por 174 municípios que estão divididos em cinco regiões metropolitanas, ${ }^{11}$ duas aglomerações urbanas ${ }^{12}$ e uma microrregião. ${ }^{13}$ Essa área ocupa $20 \%$ do território do estado de São Paulo, onde vivem mais de 30 milhões de pessoas, e representa $73 \%$ da população do estado. Ressalta-se que a localidade produz $83 \%$ da riqueza do estado e $28 \%$ do total produzido no País (ibid.). Outro ponto importante sobre esse complexo urbano regional expandido está relacionado à circulação tanto de fluxos de capital e informação, quanto de pessoas. Cunha et al. (ibid.) ressaltam que mais de dois milhões de pessoas realizavam movimentos pendulares nesse sistema de cidades, cerca de $14 \%$ da população economicamente ativa residente na macrometrópole. Além do mais, só na região metropolitana de São Paulo aproximadamente um milhão de pessoas imigra ou emigra, o que demonstra a importância do local no âmbito dos fluxos migratórios.

Figura 1 - Localização da cidade-região paulista e suas regiões

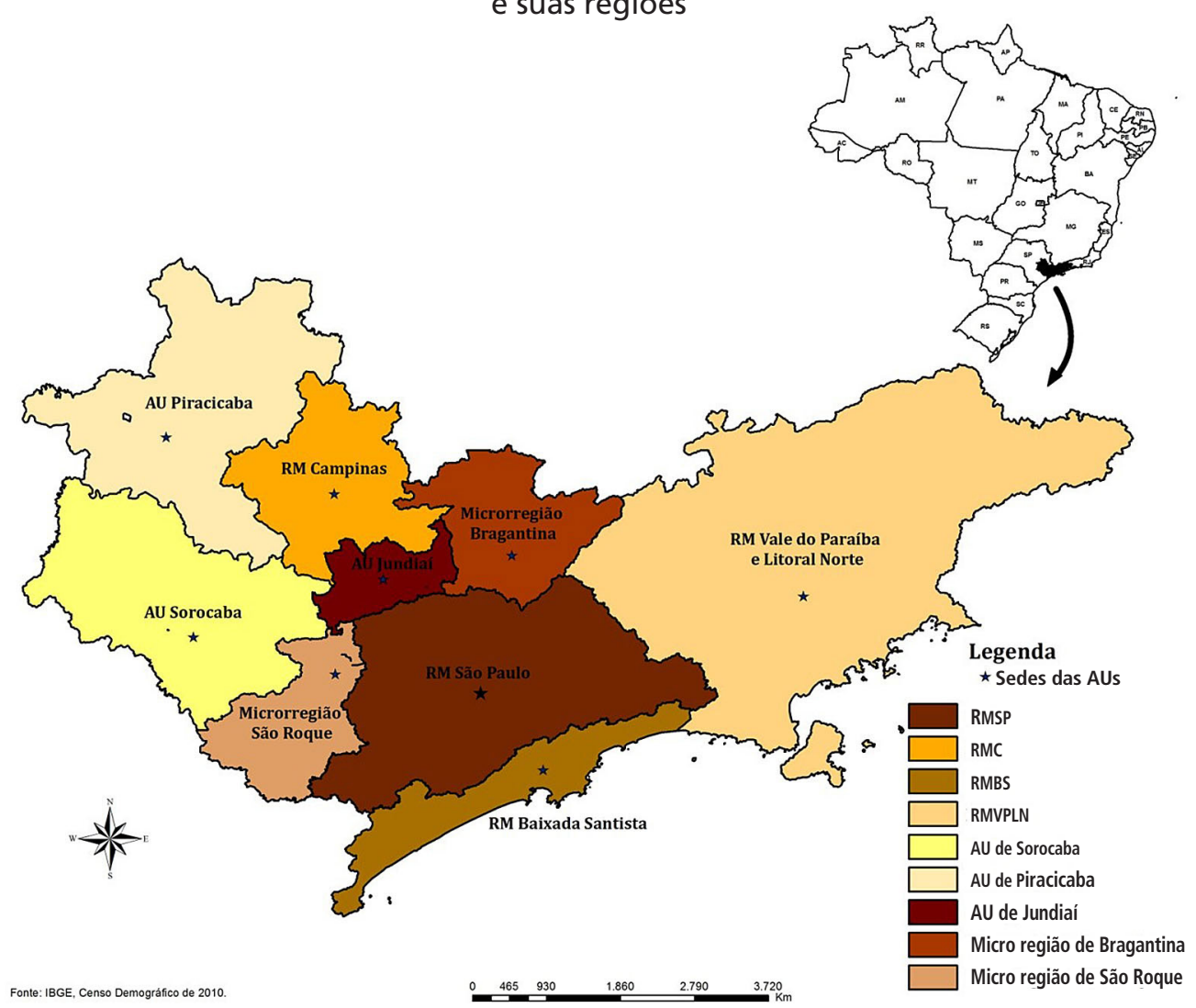

Fonte: IBGE - Malha municipal digital - 2010. 
0 presente trabalho não utiliza, contudo, o termo institucional para definir essa morfologia, que aqui passa a ser denominada "cidade-região". De maneira sintética, pode-se dizer que essa nova forma urbana materializa "as condições gerais indispensáveis à atual reestruturação produtiva, é fortemente vinculada à economia global e se caracteriza por conter estruturas econômicas, arranjos e dinâmicas que se complementam graças às redes informacionais de comunicação" (Lencioni, 2006, p. 74).

Segundo Scott et al. (2001), a formação da cidade-região relaciona-se, também, aos impactos causados pela globalização nos ambientes urbanos e nos espaços produtivos. A cidade-região, em sua dimensão regional, é caracterizada por fluxos de diversas dimensões, que perpassam distintas escalas e polarizam "um território que transcende o aglomerado principal e que aglutina outras aglomerações e centros nas proximidades, como também espaços rurais, na condução da inserção regional na divisão social do trabalho conforme demandas da produção coletiva" (Moura, 2009, p. 29).

Portanto, assim como em Lencioni (2003) e em Magalhães (2008), este trabalho conceitua a cidade-região a partir das seguintes premissas: primeiro, parte-se do entendimento de que a cidade-região pode ser compreendida como "a forma urbana do processo de metropolização em seu estágio contemporâneo, que apresenta continuidades e rupturas com os processos anteriores - como aqueles que deram origem às próprias metrópoles em contextos históricos anteriores" (Magalhães, 2008, p. 8). Em segundo lugar, destaca-se que essa morfologia emerge na era do capitalismo avançado e se coloca como nó adiante da economia globalizada. Por fim, pontua-se que a cidade- -região se conforma a partir do processo de reestruturação produtiva (Lencioni, 2003).

De modo geral, essa morfologia é caracterizada por ser "fortemente vinculada à economia global e se define por conter estruturas econômicas, arranjos e dinâmicas territoriais que se complementam graças às redes informacionais e de comunicação" (Lencioni, 2006, p. 74). É, nesse sentido, que este trabalho analisa a formação da cidade-região de São Paulo: através das dinâmicas territoriais que se complementam. Dinâmicas estas que se dão através do compartilhamento de infraestruturas, redes e serviços e que se materializam em um "espaço de fluxos" (Castells, 1999) (materiais a imateriais). Contudo, a ênfase nesta pesquisa está nos fluxos materiais, em particular, na mobilidade espacial da população.

\section{Materiais e métodos}

Para este artigo, foram utilizados os dados do censo demográfico brasileiro (IBGE) dos anos de 1991, 2000 e 2010, especialmente as informações sobre volume populacional e mobilidade populacional, ou seja, a migração e a mobilidade pendular.

Em relação aos dados referentes à migração, o quesito censitário escolhido foi o chamado "data fixa", que define o migrante como aquele que 5 anos antes do censo residia em outro município. A escolha desse quesito se justifica, não apenas pela possibilidade de comparabilidade dos três censos utilizados, mas também devido às vantagens da informação, entre elas, o estabelecimento de um período fixo de observação (5 anos) - que permite observar os movimentos de mais curto prazo. ${ }^{14}$ 
Também, com esses dados, é possível estimar, com precisão, o saldo migratório (diferença entre os imigrantes e emigrantes) e a taxa média anual de migração líquida. ${ }^{15}$

A partir dessa informação também foi possível classificar os migrantes segundo "modalidades migratórias", sendo elas: intrametropolitana, migração que ocorre entre os municípios localizados no âmbito da própria região em que já viviam; intra-CR (intra-cidade-região), migração realizada para outras regiões no âmbito da cidade-região de São Paulo, porém diferente da aglomeração residida anteriormente; intraestadual (ou outros ESP), aqueles indivíduos oriundos de outras aglomerações ou municípios não localizados na CR-paulista; interestadual, migração realizada entre estados. 0 uso dessa classificação é central no argumento deste estudo, uma vez que se pressupõe não apenas os condicionantes, mas também as motivações individuais ou familiares, variarem segundo o contexto de origem desses movimentos.

Por fim, em relação à mobilidade pendular, há uma variação na captação desse quesito nos censos de 2000 e 2010. No primeiro, a pergunta restringiu-se à realização ou não de mobilidade diária para estudo ou trabalho, sem a separação destes; já no ano de 2010 ocorreu a separação das mobilidades diárias por motivo de trabalho ou de estudo. Para este artigo, visando à compatibilização da análise, optou-se por reunir os quesitos de pendularidade para trabalho e estudo no censo de 2010 em uma só variável, como no censo de 2000, através da metodologia proposta por Cunha et al. (2013). Os pendulares internos correspondem àqueles que realizaram o movimento em municípios no interior da região em que vivem, os Externos em municípios de outras regiões e a variação corresponde à variação percentual nos pendulares em relação aos dois censos analisados (aumento ou diminuição).

\section{As contrapartidas demográficas na constituição da cidade-região paulista}

As seções anteriores buscaram destacar alguns dos processos envolvidos na constituição de novas morfologias urbanas. Por apresentar uma contínua extensão do tecido urbano e aglutinar outras regiões através de um espaço de fluxos, a cidade-região aqui tratada possui uma dinâmica demográfica própria e inerente ao atual estágio da urbanização brasileira. A configuração urbana que emerge no final do século XX possui uma complexidade maior no que tange a sua apreensão e delimitação, quando comparada com a metrópole do período industrial desenvolvimentista. Nesse sentido, no tocante a apreensão e sua delimitação territorial, esta não deve ser realizada apenas através da relação entre crescimento populacional e expansão de um continuum territorial, mas, também, pelo alcance dos fluxos e de suas relações, já que, nessa nova dinâmica, o território metropolitano permanece em processo de expansão, mesmo em tempos de declínio populacional. Destaca-se que essas não são as causas da formação da cidade-região. Contudo, a revolução ocorrida na área de transportes e comunicação favoreceu a expansão periurbana, mesmo em tempos de baixo crescimento populacional, e, também, contribuiu para a formação de uma região policêntrica. 
0 que se observa é haver uma integração cada vez maior entre algumas aglomerações urbanas, tais como as regiões metropolitanas de São Paulo, Campinas, Baixada Santista e Vale do Paraíba. Agora, uma parcela significativa da população residente no estado de São Paulo realiza as suas atividades cotidianas em uma escala metropolitana expandida e se desloca diariamente entre essas regiões. Esses descolamentos são realizados por pessoas com um perfil singular, como professores, empresários e profissionais altamente qualificados. 0 que ocorre, de acordo com Reis (2006), é uma regionalização do cotidiano:

A regionalização do cotidiano implica necessariamente 0 aumento da mobilidade da população e dos serviços. 0 sistema implantado no mercado de trabalho pelo setor industrial terminou por induzir também a mobilidade nas áreas de comércio, nos serviços, no ensino e no lazer. As oportunidades oferecidas pelo comércio e pelos serviços já não são analisadas pelos empresários em escala local, mas em escala regional, pressupondo uma mobilidade constante dos habitantes dessas regiões, na oferta de serviços. (p. 92)

Portanto, com a formação de novas morfologias urbanas, observam-se, também, mudanças na dinâmica demográfica (em espacial na mobilidade espacial da população), pois, com a expansão do processo de metropolização e com a dilatação do tecido urbano, o espaço de vida cotidiano passa a se desenvolver em diversas escalas, ou seja, "o fazer a vida" se dá sobre novas bases territoriais.

\section{Os processos de expansão}

De acordo com o relatório produzido pelo Fundo de População das Nações Unidas (UNFPA, 2007), o ano de 2008 seria marcado pela transição da população global de rural para urbana. Tal fato se concretizou e, no século XXI, mais da metade da população mundial vive em áreas urbanas. A transição urbana brasileira, assim como em outros países da América Latina, não é recente e data de meados da década de 1960, período assinalado por um vertiginoso crescimento populacional, fruto das altas taxas de natalidade e de grandes fluxos migratórios do tipo rural-urbano. Em apenas trinta anos, a população brasileira mudou seu status de rural para urbana: em 1950, cerca de 18 miIhões de pessoas residiam em áreas urbanas, o que representava um percentual de $36 \%$ da população total. Já, em 1980, o percentual de urbanização subiu para $68 \%$, com mais de 80 milhões de habitantes situados dentro de perímetros urbanos (Faria, 1991). De acordo com Faria (ibid.), o crescimento populacional nesse período foi marcado por duas vertentes: a primeira, uma intensa concentração populacional em poucas metrópoles; e a segunda, um processo de redistribuição espacial da população em cidades de diferentes portes populacionais.

Portanto, como explicitado anteriormente, as áreas metropolitanas entre as décadas de 1960 a 1980 apresentaram um ligeiro crescimento, principalmente em seus núcleos. Contudo, o final dos anos de 1980 foi caracterizado por um arrefecimento no crescimento 
das metrópoles. Para muitos autores, essa fase é demarcada pela chamada desmetropolização e está atrelada ao processo de desconcentração industrial e de deseconomias de aglomeração ${ }^{16}$ (Araujo, Moura e Dias, 2011). Para Martine (1994), o arrefecimento do crescimento metropolitano foi marcado pela expansão do processo de periferização das metrópoles. 0 autor destaca que "em todas as RMs, exceto Belém, a taxa de crescimento dos municípios periféricos foi significativamente superior à dos seus respectivos municípios núcleos" (p. 34). Ou seja, as metrópoles ainda apresentavam um crescimento populacional, mesmo com a cidade principal crescendo menos em termos de população em relação aos demais municípios da área.

Segundo Cunha (2003), os anos de 1980 demarcam a transformação na dinâmica econômica, social e demográfica, com rebatimentos nos processos de redistribuição espacial da população, em que novas localidades e outros tipos de deslocamentos ganharam importância. Porém, para o autor, esse processo de desconcentração populacional deve ser relativizado, pois está circunscrito às regiões metropolitanas de São Paulo e Rio de Janeiro. Ou seja, o processo de involução metropolitana deve ser relativizado, já que as metrópoles brasileiras continuam influenciando o crescimento de muitos núcleos urbanos de porte médio em expansão. Porém, esses municípios estão localizados, em grande parte, em áreas metropolitanas ${ }^{17}$ ou próximo a elas, fato demonstrado por Cunha, Silva e Alonso (2015) para o estado de São Paulo.

Esse transbordamento populacional para as áreas adjacentes à RMSP pode indicar uma integração urbana. Ou seja, a reestruturação produtiva perpassada no estado de São Paulo e o espraiamento populacional iniciado pela RMSP podem indicar uma forte integração entre as áreas que participam desse processo, bem como um compartilhamento de um sistema produtivo, de infraestruturas e de uso do solo que dilata da RMSP para outras regiões em um raio de $200 \mathrm{~km}$. Destaca-se que a estrutura industrial do estado presente em um conjunto de regiões possibilitou a formação de sistemas produtivos centrais, bem como uma forte integração funcional entre as demais regiões (RMSP, RMC, RMBS, RMVPLN, entre outras). Nesse sentido, o processo de desconcentração industrial foi demarcado por mudanças na dinâmica populacional, e o interior de São Paulo passou a apresentar taxas de crescimento populacional mais elevadas do que a metrópole paulista (Tabela 1), resultado do processo de desconcentração populacional protagonizado pela RMSP (Cano et al., 2007).

Para autores como Reis (2006), no final da década de 1980 e no decorrer dos anos de 1990, pode-se observar uma vertiginosa expansão da área metropolitana. Essa dilatação do perímetro metropolitano está relacionada com processos como a reestruturação produtiva e a globalização que, como visto anteriormente, mudaram as lógicas de reprodução do capital no espaço e formaram novos arranjos espaciais. Ainda de acordo com Reis (ibid.), a expansão metropolitana nas últimas décadas foi assinalada por um processo de caráter geral denominado dispersão urbana, que está vinculado com o processo de descontração industrial, e também por uma crescente mobilidade espacial da população. Para esse mesmo autor, a dispersão urbana é caracterizada pela difusão do processo de urbanização que se estende por 
um amplo território e atinge diversos núcleos urbanos com espaços intersticiais, porém com vínculos profundos entre si, o que caracteriza a formação de um único sistema urbano.

Pontua-se que essa morfologia urbana dispersa é assinalada por espaços urbanos descontínuos, áreas rurais e núcleos urbanos de diversos tamanhos e com distintas funções. Também, observa-se que a população residente, tanto em grandes centros urbanos, quanto em núcleos de pequeno porte ou em áreas rurais, passa a adotar novos modos de vida e são caracterizadas por maior mobilidade. Portanto, a dispersão urbana ou a difusão do periurbano, como nomeia De Mattos (2004), é marcada pela expansão do processo de metropolização e, consequentemente, pela ampliação do espaço de vida cotidiano para uma escala metropolitana, intermetropolitana ou até mesmo regional. Nessa ampliação do espaço de assentamento e circulação do cidadão metropolitano, torna-se necessário considerar novas escalas espaciais de análise, ou seja, a expansão do processo de metropolização exige uma perspectiva mais regional de análise. Tais transformações podem ser evidenciadas na porção sudoeste do estado de São Paulo, com a intensa conexão de diversos aglomerados urbanos como a região metropolitana de São Paulo, Campinas, Santos e Vale do Paraíba.

Segundo Sposito (2007), as aglomerações metropolitanas, não metropolitanas e algumas cidades do interior de São Paulo tiveram seu papel e função de centros redefinidos com desconcentração produtiva. Esse processo de desconcentração definiu e delimitou os chamados eixos de desenvolvimento que, agora, se caracterizaram pela união de polos da rede urbana e são interconectados por fluxos de pessoas e de mercadorias, mas indo além das vias de transportes, sendo também conectados por vias áreas, por infovias de telefonias, de fibra ótica, entre outros fluxos materiais e de informações. Para Lencioni (2003), esses eixos de expansão no estado de São Paulo conjugam a formação da chamada Cidade-Região Paulista (CR-P), sendo conectada por fluxos e pela definição de novas funções dentro do sistema de cidades. Portanto, a formação desse eixo pressupõe um conjunto de atividades complexas e uma complementaridade regional que, ao longo dos eixos, se dá de forma direta com a RMSP.

Nesse sentido, a Tabela 1 demonstra o comportamento das taxas de crescimento populacional das áreas que formam a Cidade-Região Paulista (CR-P) nos últimos 30 anos. Observa-se, através dessa informação, além da expressiva concentração populacional do estado de São Paulo nessa porção territorial (cerca de 75\%), o declínio nas taxas anuais de crescimento populacional em todas as áreas que englobam a CRP no comparativo 1991/2000 e 2000/2010. Contudo, mesmo com esse decréscimo, nota-se que as regiões que formam a cidade-região, exceto seu núcleo central (RMSP), apresentaram crescimento populacional superior à média regional no decênio 2000/2010.

Destaca-se, também, que a cidade-região como um todo apresentou um ligeiro aumento no peso relativo nos anos analisados. Esse fato foi influenciado principalmente pelo crescimento da RMC que, nos últimos anos, apresentou aumento no peso relativo da população nos três anos em análise. Já as outras regiões demonstraram manutenção ou ligeiro aumento desse peso, em função da perda do peso relativo da região metropolitana de São Paulo. 


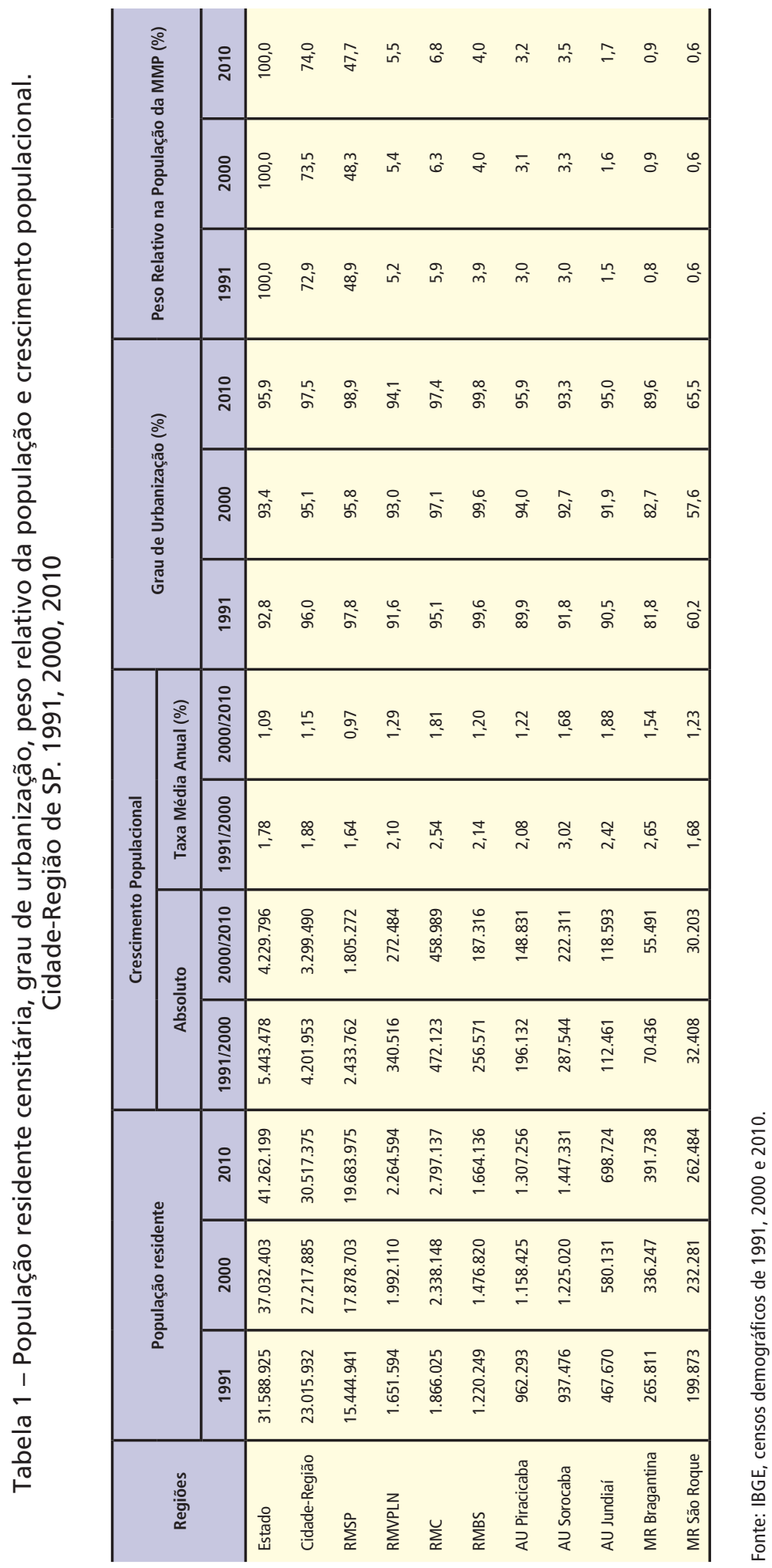


Nesse sentido, a desconcentração populacional da RMSP, bem como das sedes das demais regiões da cidade-região paulista, pode ser evidenciada na Figura 2. Percebem-se, através dessa Figura, alguns vetores de expansão ou um espraiamento do arranjo regional, oriundo de uma periferização das regiões, considerando o aumento do crescimento médio anual dos municípios nas franjas dessas regiões.

Ressalta-se que a expansão ou o crescimento das bordas da área metropolitana de São Paulo se iniciou no período industrial desenvolvimentista e passou a prenunciar a formação da cidade-região (De Mattos, 2004). Contudo, é preciso pontuar que o processo de periferização no Brasil está associado à crescente "espoliação urbana", que se configurou a partir da massiva concentração da população pobre e trabalhadora nas áreas periféricas das grandes aglomerações urbanas. Essa completa desordem - que, como nos mostra Kowarick (1982), possui uma lógica - acompanhou o crescimento das cidades brasileiras e possui relações com o capital imobiliário e

Figura 2 - Vetores da taxa crescimento médio anual por município. Cidade-região de SP. 2000 e 2010

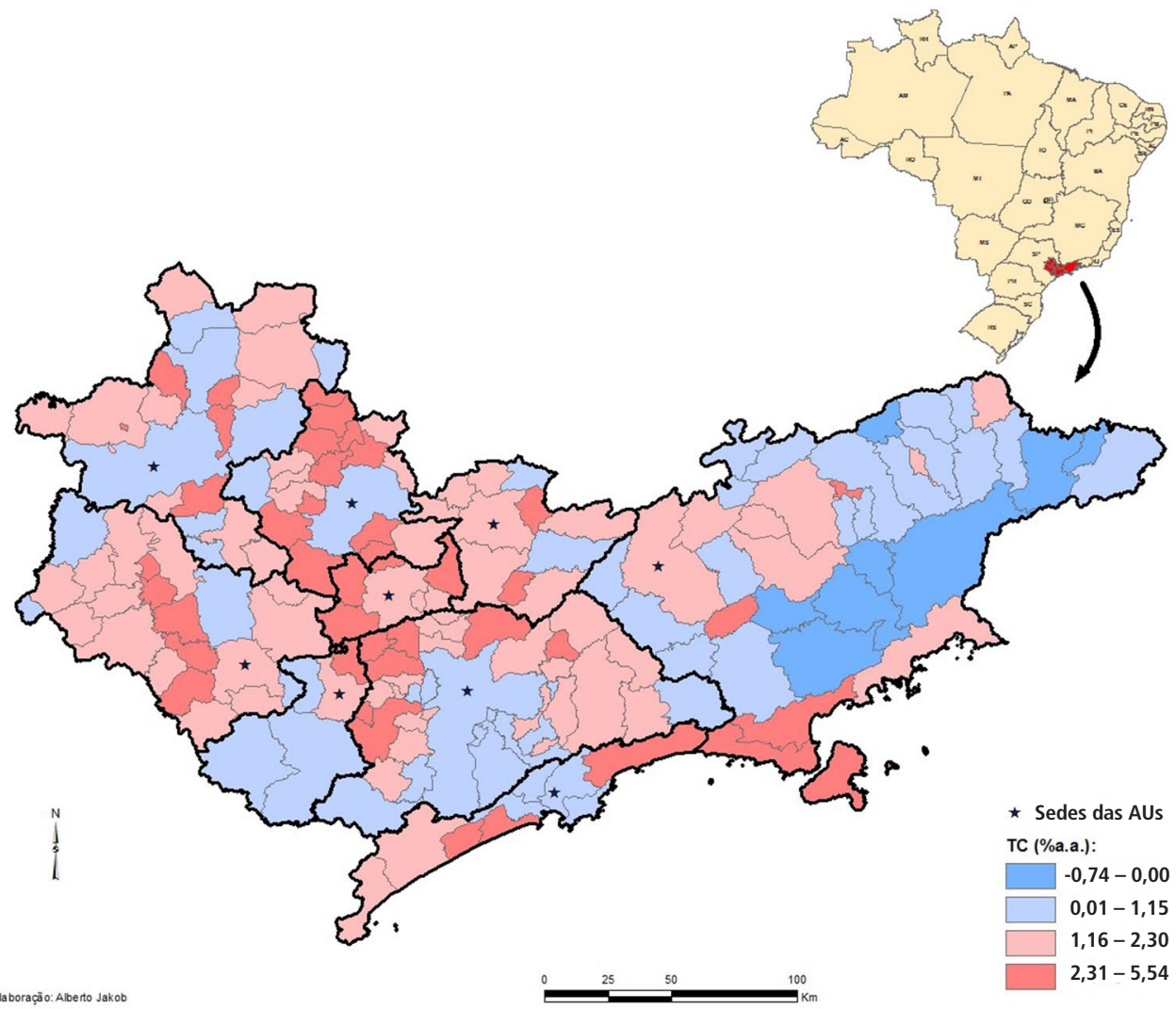

Fonte: IBGE - malha municipal digital - 2010. 
suas lógicas de organização do espaço através da valorização de algumas áreas e desvalorização de outras, bem como a criação de reservas de valores. Porém, cabe salientar que as transformações socioeconômicas nas áreas metropolitanas, sob efeito do processo de globalização e reestruturação produtiva, impulsionaram ainda mais o fenômeno de dilatação das bordas metropolitanas.

Portanto, é necessário enfatizar que esse processo pode estar relacionado com 0 aumento do preço da terra, bem como dos serviços nos grandes centros, o que determina, invariavelmente, a desconcentração populacional e industrial destes em direção aos municípios que estão ao seu redor. Esse fato possibilitou cada vez mais a aglomeração e a interligação das regiões da CRP, principalmente na região noroeste (Região Metropolitana de Campinas e de Sorocaba, Aglomeração Urbana de Jundiaí e de Piracicaba), como observado na Figura 2.

Assim, no sentido das mudanças apresentadas anteriormente, é importante ressaltar que, nesse novo quadro metropolitano, antigas lógicas de produção do espaço urbano coexistem com lógicas atuais. Por exemplo, o modelo centro-periferia - que norteou a compreensão do crescimento urbano na segunda metade do século XX - ainda se faz presente e coexiste com as chamadas periferias elitizadas. Nesse sentido, têm-se as lógicas do mercado imobiliário incidindo sobre o processo de redistribuição espacial da população, principalmente no espaço intrametropolitano; mas também se observa a ação do processo de reestruturação produtiva sobre essa redistribuição populacional, porém em uma escalar maior do que no espaço intrametropolitano.
É importante pontuar que esse processo de restruturação produtiva e a redistribuição espacial da população estão relacionados, tal qual afirma Diniz e Diniz (2007), com a qualidade da malha viária que detém a CR-P e que possibilita uma intensa comutação entre os espaços da cidade-região, bem como uma integração funcional entre os seus centros. Além dessa intensa comutação, que será demonstrada nas sessões a seguir, nota-se um crescimento dos fluxos migratórios intrarregionais, que podem ter sido influenciados pelas demandas por mão de obra nesse quadro de reestruturação.

\section{As novas lógicas de integração e complementaridade: os fluxos populacionais}

Como já reiterado, algumas metrópoles em seu processo de metamorfose ampliam e estreitam suas relações com outras localidades através do aumento dos fluxos materiais e imateriais. A cidade-região, em sua dimensão regional, é caracterizada por fluxos de diversas dimensões, que perpassam distintas escalas e polarizam "um território que transcende o aglomerado principal e que aglutina outras aglomerações e centros das proximidades, como também espaços rurais, na condução da inserção regional na divisão social do trabalho conforme demandas da produção coletiva" (Moura, 2009, p. 29).

Portanto, a metrópole metamorfoseada é caracterizada pela predominância do "espaço dos fluxos sobre o espaço dos lugares" (Lencioni, 2008, p. 19). E, para apreender a formação e estruturação dessa nova morfologia, é necessário analisá-la segundo uma visão 
multiescalar, ou seja, de acordo com Lencioni (ibid.), é imprescindível analisar essa nova forma urbana através da lógica dos fluxos topográficos e topológicos. $^{18}$

Apesar de este trabalho estar centrado na lógica topográfica dos fluxos, a apreensão da cidade-região nesse âmbito, ou seja, através dos fluxos materiais, também está calcada em uma visão multiescalar. Nesse sentido, a multidimensionalidade de escalas que se pretende apreender neste trabalho está relacionada aos diversos processos de conformação da metrópole metamorfoseada segundo os fluxos materiais. Assim, se a mobilidade espacial da população na escala intrametropolitana revela certas lógicas de produção do espaço urbano - a exemplo, o agir do mercado de terras em suas diversas formas -, da mesma maneira a análise da mobilidade em uma escala inter-regional pode evidenciar processos relacionados à reestruturação produtiva, como, por exemplo, a migração ou a mobilidade pendular de alguns indivíduos que estão inseridos em certos setores de atividades da economia.

Destaca-se que a dinâmica demográfica e, em especial, o fenômeno da mobilidade espacial da população apresentam algumas especificidades de acordo com cada fase do processo de urbanização brasileira e com a constituição de determinadas territorialidades. Nesse sentido, este trabalho tem como pressuposto que a formação de novas morfologias urbanas no Brasil se relaciona com as mudanças no fenômeno da mobilidade, em especial como o aumento dos movimentos pendulares e da migração de curta distância. Dado esse panorama, esta seção fará um breve resgate sobre essas transformações que perfazem o processo de redistribuição espacial da população e focalizará nas transformações e nas tendências que demarcam o fenômeno da mobilidade espacial da população na cidade-região paulista nos últimos trinta anos.

Devido à progressiva queda da fecundidade que caracterizou a segunda metade do século XX, a migração aumentou sua participação no processo de redistribuição espacial da população. No entanto, nos anos de 1980, percebe-se que o crescimento das metrópoles brasileiras foi afetado pela queda significativa da migração, em especial pela redução dos grandes fluxos migratórios, particularmente aqueles do tipo rural-urbano que, como se sabe, no passado ditavam o compasso do fenômeno migratório (Cunha, 2011 e Cunha, 2015).

No entanto, o declínio da migração do tipo rural-urbano, em geral representado pelos movimentos de mais longa distância, permitiu que fossem evidenciadas outras formas de mobilidade, tais como a migração dos tipos urbano-urbano, intraestadual, intrametropolitana e a mobilidade pendular, que passaram a ser mais preponderantes no âmbito das grandes cidades.

Nesse sentido, é interessante observar a evolução do processo migratório e do peso que este tem no processo de redistribuição espacial da população na cidade-região paulista. Nota-se, através da Tabela 2, que o peso da migração na CR caiu vertiginosamente, assim como em todo o estado de São Paulo, nos períodos 1991/2000 e 2000/2010. A exceção está na região metropolitana de Campinas e na aglomeração urbana de Jundiaí. A primeira foi demarcada por um expressivo aumento da participação da migração no crescimento populacional, fato que justifica a significativa taxa de crescimento que caracteriza a região nos últimos anos. 
Destaca-se que a RMC foi beneficiada pela desconcentração industrial da cidade de São Paulo, bem como pelo aumento do parque industrial de cidades ao redor da sede da região, como Paulínia, Hortolândia e Indaiatuba. Já, o crescimento da AU de Jundiaí foi beneficiado pela proximidade da cidade de São Paulo e atraiu pendulares. ${ }^{19}$ Em contrapartida, observa-se que a RMSP passou a ter peso relativo negativo da migração, mas esse fato não tipifica a região como pouco atrativa do ponto de vista migratório, já que continua sendo a região que recebe o maior número de migrantes em termos absolutos. Contudo, a RMSP no período atual é demarcada por forte potencial endógeno redistributivo da população, ou seja, ao mesmo tempo que recebe um fluxo expressivo de imigrantes interestaduais, ela também redistribui sua população para os municípios e aglomerações urbanas ao seu redor através de fluxos intrametropolitanos, intracidade região e intraestadual.

Portanto, o que se observa, através da Tabela 2, é que a migração possui um papel preponderante no crescimento populacional de alguns aglomerados que compõem a cidade-região paulista. Contudo, é preciso analisar qual modalidade migratória possui maior relevância nesse crescimento. Nesse sentido, a análise da distribuição da composição da migração por modalidades migratórias pode nos dar um indicativo da complementaridade entre as regiões, ao analisar as trocas migratórias através da modalidade do fluxo. Por exemplo, o aumento da migração intrarregional e sua participação no crescimento da população

Tabela 2 - Crescimento migratório, peso relativo, saldos e taxas migratórias. Cidade-região de SP 1991, 2000 e 2010

\begin{tabular}{l|c|c|c|c|c|c}
\hline \multirow{2}{*}{ Regiões } & \multicolumn{4}{|c|}{ Migração } & \multicolumn{2}{c}{$\begin{array}{c}\text { Peso Relativo } \\
\text { da Migração }\end{array}$} \\
\cline { 2 - 6 } & \multicolumn{2}{|c|}{ Saldo Migratório } & \multicolumn{2}{c}{ Taxa Média Anual } & \multicolumn{2}{c}{1} \\
\cline { 2 - 5 } & $1991 / 2000$ & $2000 / 2010$ & $1991 / 2000$ & $2000 / 2010$ & $1991 / 2000$ & $2000 / 2010$ \\
\hline Estado & 1.326 .987 & 472.650 & 0,43 & 0,12 & 24,38 & 11,17 \\
Cidade-Região & 1.024 .398 & 290.570 & 0,45 & 0,10 & 24,38 & 8,81 \\
RMSP & 219.591 & -299.680 & 0,15 & $-0,16$ & 9,02 & $-16,60$ \\
RMVPLN & 111.222 & 65.690 & 0,68 & 0,31 & 32,66 & 24,11 \\
RMC & 237.897 & 231.940 & 1,27 & 0,91 & 50,39 & 50,53 \\
RMBS & 118.035 & 50.170 & 0,98 & 0,32 & 46,00 & 26,78 \\
AU Piracicaba & 84.411 & 51.990 & 0,89 & 0,42 & 43,04 & 34,93 \\
AU Sorocaba & 146.070 & 102.790 & 1,51 & 0,77 & 50,80 & 46,24 \\
AU Jundiaí & 52.416 & 56.330 & 1,12 & 0,88 & 46,61 & 47,50 \\
MR Bragantina & 36.648 & 25.400 & 1,36 & 0,70 & 52,03 & 45,77 \\
MR São Roque & 18.108 & 5.940 & 0,93 & 0,24 & 55,88 & 19,67 \\
\hline
\end{tabular}

Fonte: IBGE, censos demográficos de 1991, 2000 e 2010. 
elucidam a importância das trocas migratórias no âmbito da cidade-região para sua estruturação. Os Gráficos 1 e 2 trazem a composição da migração segundo modalidade migratória para os períodos de 1995/2000 e 2005/2010, para algumas regiões metropolitanas selecionadas da cidade-região paulista. ${ }^{20}$

Ao analisar a composição da migração por modalidades migratórias, percebe-se que a RMSP sempre foi caracterizada como a "porta de entrada" de imigrantes interestaduais no estado de São Paulo. Através dos Gráficos 1 e 2 , percebe-se que os fluxos interestaduais são preponderantes nessa região. Porém, nota-se que, entre 2000 e 2010, a migração do tipo intra-AU (entre as regiões que compõem a $C R$ ) ganhou peso relativo na RMSP, justamente em função da redução dos fluxos interestaduais. Em outras palavras, a análise das modalidades migratórias entre os períodos é relevante, uma vez que permite observar a mudança da preponderância dos movimentos interestaduais para aqueles de mais curta distância.

Tal fato demonstra a relevância que os movimentos populacionais vêm adquirindo nesse espaço urbano regional. Ou seja, o aumento da migração entre os municípios que compõem a cidade-região Paulista pode indicar uma relação de complementaridade entre os fragmentos que formam essa unidade. Suscita-se que os indivíduos que residem na CR-P, ${ }^{21}$ com o avanço do processo de metropolização e o compartilhamento de um mercado trabalho através do processo de reestruturação produtiva, ampliam o espectro de seu espaço de vida, bem como a possibilidade de migrar para outras áreas no âmbito da cidade-região.
A Figura 3 demonstra a relação de complementaridade entre as áreas da CRP, ao demonstrar os fluxos migratórios entre as regiões. Percebe-se que parte destes fluxos se dá entre a RMSP e as outras regiões, ou seja, a região metropolitana de São Paulo se perfaz como nó nesse complexo metropolitano expandido. Porém, ao analisar os fluxos entre os dois períodos, percebe-se o aumento dos fluxos entre outras regiões além da RMSP, por exemplo, entre Campinas e Sorocaba.

Um outro fluxo capaz de demonstrar e refletir a integração dessa morfologia que é dispersa é o chamado movimento pendular (Lencioni, 2006 e Parr, 2005). Essa tipologia de movimento adquiriu crescente visibilidade nas grandes cidades nas últimas décadas, devido a sua associação com as demandas por transporte e vias de circulação, e incide de maneira decisiva no funcionamento cotidiano e na projeção estratégica das cidades, tanto para pessoas como para empresas e instituições. São esses fluxos de pessoas realizados no cotidiano que possibilitam a captação da dinâmica das relações entre as diversas partes que constituem a cidade-região. A Tabela 3 traz volume e peso relativo da mobilidade pendular sobre a População em Idade Ativa (PIA) para algumas das regiões da cidade-região de São Paulo para os períodos de 2000 e 2010.

Através dessa Tabela, observa-se o aumento no número de pessoas que realizam o movimento pendular em todas as regiões analisadas. Nota-se que o maior volume de pendulares se registra na RMSP, o que está, obviamente, ligado ao porte populacional que essa região possui. Contudo, ao relativizar essa informação, 
Gráficos 1 e 2 - Composição da migração por modalidade migratória.

Regiões metropolitanas selecionadas, 1995/2000 e 2005/2010

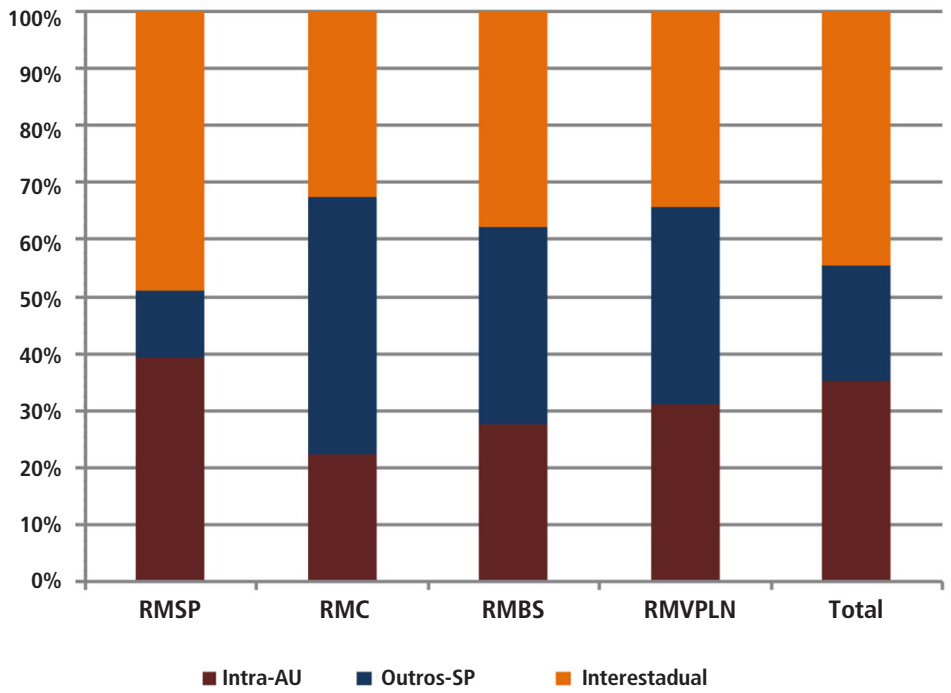

Fonte: IBGE, censos demográficos de 2000 e 2010.

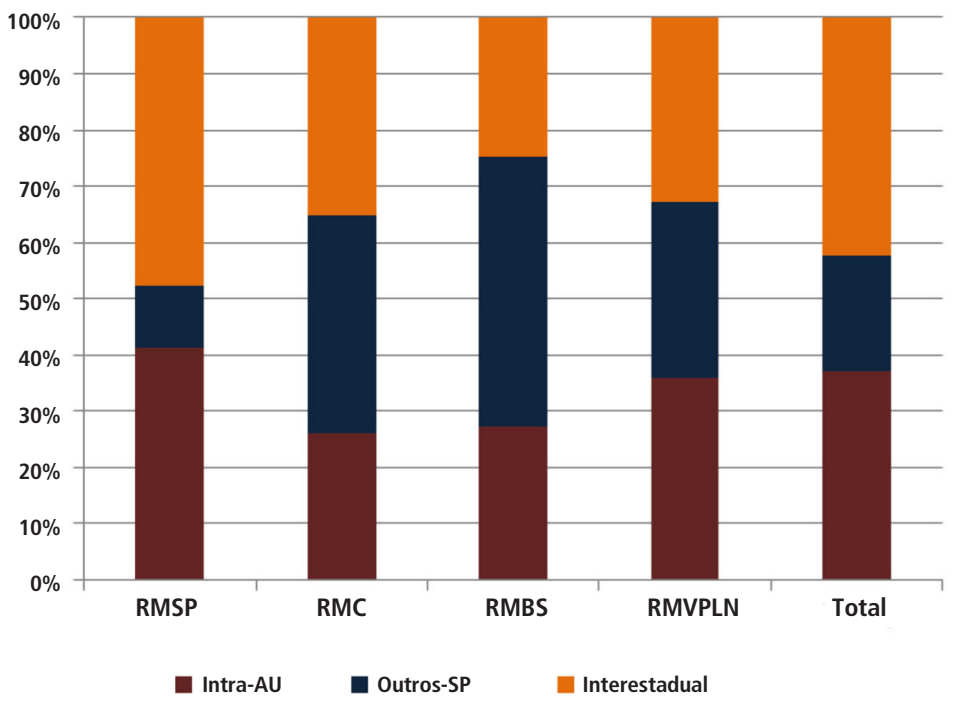

Fonte: IBGE, censos demográficos de 2000 e 2010. 
Figura 3 - Fluxos migratórios acima de 3 mil pessoas entre as regiões.

Cidade-região paulista, 1995-2000 e 2005-2010

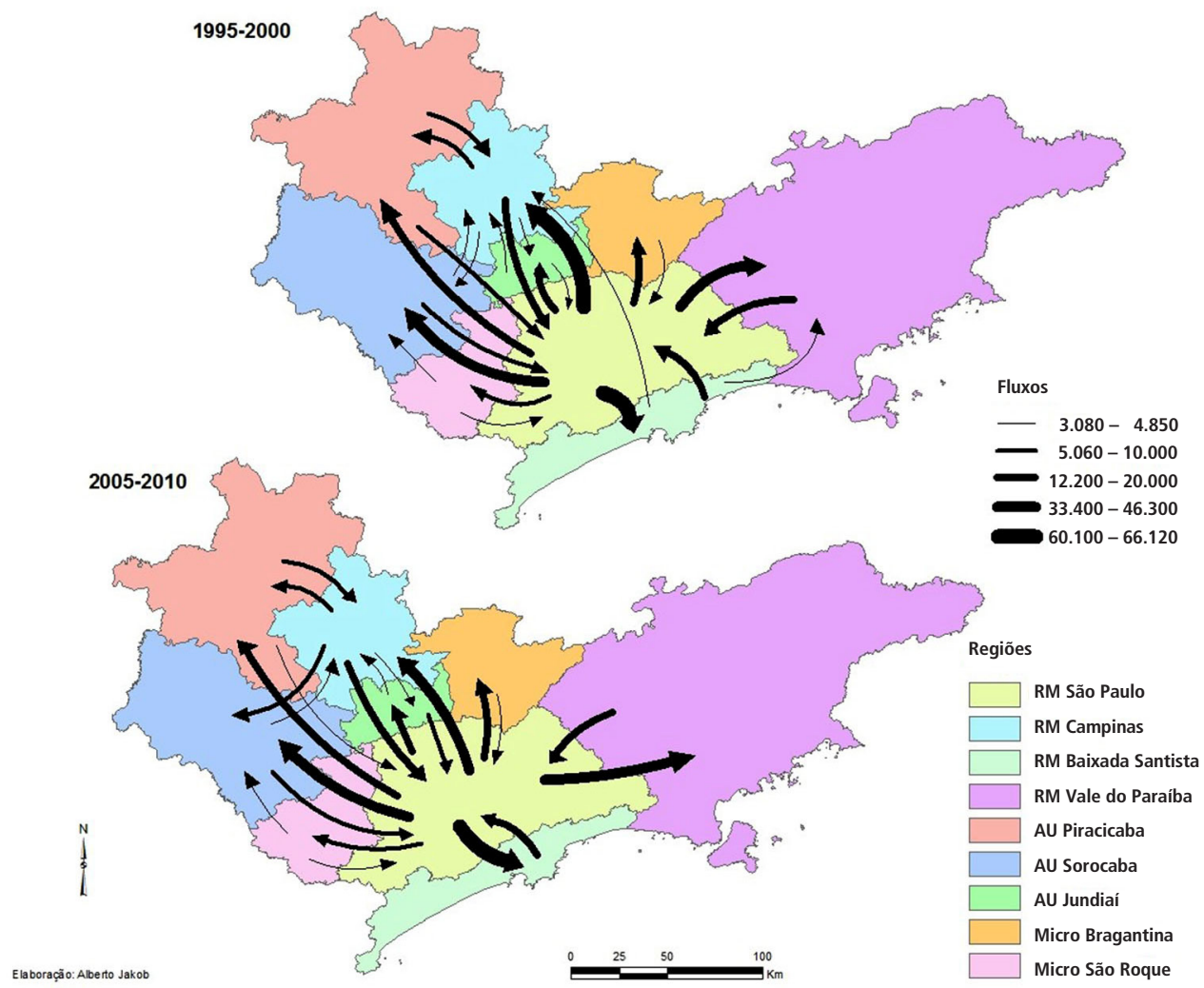

Fonte: IBGE - malha municipal digital - 2010.

Tabela 3 - Volume e peso relativo da mobilidade pendular sobre a População em Idade Ativa (PIA) residente na região.

Regiões metropolitanas do estado de São Paulo, 2000 e 2010

\begin{tabular}{l|c|c|c|c}
\hline \multirow{2}{*}{ Regiões } & \multicolumn{2}{|c|}{ Volume dos movimentos pendulares } & \multicolumn{2}{c}{ Percentual da PIA } \\
\cline { 2 - 5 } & 2000 & 2010 & 2000 & 2010 \\
\hline RMC & 171.033 & 311.992 & 9,8 & 14,02 \\
RMSP & 1.108 .691 & 1.942 .001 & 8,4 & 12,65 \\
RMBS & 128.064 & 201.023 & 11,7 & 15,51 \\
RMVPLN & 84.621 & 149.597 & 5,9 & 8,50 \\
Outros CR & 162.253 & 321.610 & 6,3 & 9,80 \\
Total & 1.654 .662 & 2.926 .216 & 9,5 & 14,18 \\
\hline
\end{tabular}

Fonte: IBGE, censos demográficos de 2000 e 2010. 
ou seja, considerando o peso desse tipo de movimento entre os indivíduos em idade ativa, percebe-se claramente que esse fenômeno é mais intenso nas regiões metropolitanas de Campinas e Baixada Santista.

Embora seja preciso considerar que tais movimentos ocorrem com mais frequência no âmbito intrametropolitano, fica muito claro que eles ocorrem em diversas escalas e, no caso da CRP, o fenômeno é bem significativo. Assim, chama a atenção o aumento da mobilidade externa da RMSP - variação de mais de 210\% nos 10 anos de análise - e da mobilidade interna na CR como um todo - mais de $107 \%$ de variação (Tabela 4). Assim, mais do que uma integração no âmbito intrametropolitano, esses dados demonstram também um aumento da mobilidade pendular entre as regiões que englobam a $C R$, já que a mobilidade externa teve uma variação maior no período em análise do que a migração interna na $C R$, RMC, RMSP e RMBS.
Como já mencionado, do ponto de vista demográfico, em geral, e dos fluxos de pessoas, em particular, a complementaridade regional, para a qual chamamos a atenção, tenderia a expressar-se através de duas grandes dimensões: o mercado de terras e o mercado de trabalho. No primeiro caso, acredita-se que a mobilidade residencial intensa e em expansão seria o elemento que melhor caracterizaria tal fenômeno; já, no segundo caso, ou seja, o mercado de trabalho, certamente a mobilidade pendular entre as regiões seria a que melhor refletiria tal condição.

De maneira a sustentar tal proposição, construiu-se a Tabela 5, que cruza a condição migratória e de pendularidade dos indivíduos. Por meio desses dados é possível perceber, por um lado, que a migração com origem na própria RM (intrametropolitana) parece ter motivação muito mais intensa na questão habitacional, uma vez que o percentual de pessoas que, mesmo tendo mudado de município,

Tabela 4 - Volume e variação da mobilidade pendular interna, externa e total. Regiões metropolitanas paulistas e municípios da cidade-região paulista. 2000 e 2010

\begin{tabular}{|c|c|c|c|c|c|c|c|c|c|}
\hline \multirow{3}{*}{ Regiões } & \multicolumn{9}{|c|}{ Mobilidade Pendular } \\
\hline & \multicolumn{3}{|c|}{2000} & \multicolumn{3}{|c|}{2010} & \multicolumn{3}{|c|}{ Variação (\%) } \\
\hline & Interno & Externo & Total & interno & Externo & Total & Interno & Externo & Total \\
\hline RMC & 134.796 & 35.543 & 171.033 & 241.077 & 70.915 & 311.992 & 78,85 & 99,52 & 82,42 \\
\hline RMSP & 1.015 .221 & 89.162 & 1.108 .691 & 1.663 .374 & 278.627 & 1.942 .001 & 63,84 & 212,50 & 75,16 \\
\hline RMBS & 102.380 & 25.451 & 128.064 & 160.346 & 40.677 & 201.023 & 56,62 & 59,82 & 56,97 \\
\hline RMVPLN & 63.028 & 21.103 & 84.621 & 115.556 & 34.041 & 149.597 & 83,34 & 61,31 & 76,78 \\
\hline Outras Macrometrópoles & 99.731 & 61.557 & 162.253 & 207.299 & 114.311 & 321.610 & 107,86 & 85,70 & 98,22 \\
\hline Total & 1.415 .156 & 232.816 & 1.654 .662 & 2.387 .652 & 538.571 & 2.926 .223 & 68,72 & 131,33 & 76,85 \\
\hline
\end{tabular}

Fonte: IBGE - censos demográficos de 2000 e 2010. 
Tabela 5 - Migrante de data-fixa em idade ativa segundo modalidade e origem de grupo de municípios de trabalho, por regiões metropolitanas do estado de São Paulo. Cidade-região paulista, 2010

\begin{tabular}{|c|c|c|c|c|c|c|}
\hline \multirow{2}{*}{$\begin{array}{l}\text { Modalidade } \\
\text { Migratória }\end{array}$} & \multirow{2}{*}{ Município de trabalho } & \multicolumn{4}{|c|}{ Região em 2010} & \multirow{2}{*}{ Total } \\
\hline & & RMSP & RMC & RMBS & RMVPLN & \\
\hline \multirow{5}{*}{ Intrametropolitana } & Próprio município & 42,0 & 40,0 & 40,8 & 69,2 & 43,9 \\
\hline & Município em 2005 & 34,6 & 30,6 & 33,7 & 18,3 & 32,8 \\
\hline & Outro município da RM & 20,5 & 3,7 & 18,1 & 8,0 & 17,5 \\
\hline & Outro município & 2,9 & 25,7 & 7,4 & 4,5 & 5,8 \\
\hline & Subtotal & 127.776 & 18.422 & 12.274 & 13.850 & 172.321 \\
\hline \multirow{5}{*}{ Intra-CR } & Próprio município & 78,4 & 53,5 & 66,6 & 79,8 & 67,8 \\
\hline & Município em 2005 & 2,7 & 6,0 & 14,7 & 5,8 & 7,0 \\
\hline & Município da RM & 15,2 & 11,9 & 12,4 & 8,4 & 12,4 \\
\hline & Outro município & 3,6 & 28,7 & 6,3 & 6,0 & 12,9 \\
\hline & Subtotal & 18.243 & 21.106 & 14.225 & 10.195 & 63.769 \\
\hline \multirow{5}{*}{ Outros ESP } & Próprio município & 80,1 & 66,3 & 72,6 & 83,7 & 75,4 \\
\hline & Município em 2005 & 1,1 & 1,5 & 2,7 & 1,4 & 1,4 \\
\hline & Município da RM & 15,0 & 12,7 & 16,9 & 7,4 & 13,9 \\
\hline & Outro município & 3,8 & 19,5 & 7,8 & 7,5 & 9,3 \\
\hline & Subtotal & 14.244 & 8.540 & 2.367 & 1.836 & 26.988 \\
\hline \multirow{5}{*}{ Interestadual $\left({ }^{*}\right)$} & Próprio município & 83,2 & 66,1 & 72,3 & 87,4 & 80,5 \\
\hline & Município em 2005 & 0,4 & 1,0 & 0,7 & 0,7 & 0,5 \\
\hline & Município da RM & 14,0 & 15,2 & 21,6 & 6,7 & 14,0 \\
\hline & Outro município & 2,4 & 17,7 & 5,3 & 5,2 & 4,9 \\
\hline & Subtotal & 124.497 & 24.295 & 8.928 & 13.071 & 170.792 \\
\hline \multicolumn{2}{|r|}{ Total } & 284.760 & 72.363 & 37.795 & 38.951 & 433.869 \\
\hline
\end{tabular}

Fonte: IBGE - censos demográficos de 2000 e 2010.

ainda trabalha naquele de residência anterior é significativo. Tal percentual varia de $18,3 \%$ na RMVPLN até 34,6\% na RMSP.

Por outro lado, no caso dos migrantes que se mudam para outras regiões da CRP, a situação é distinta, uma vez que a maior parte destes passa a trabalhar no município de destino. No entanto, mesmo assim, essa situação é diferenciada, ao se analisar as RMs do "interior" de São Paulo, a RMC e RMBS: o percentual de pessoas que, mesmo tendo mudado de região, ainda trabalham fora dela é bem significativo, alcançando 34,7\% em Campinas e $21 \%$ na Baixada Santista. ${ }^{22}$

Enfim, particularmente para essas duas regiões (RMC e RMBS), que mais se conectam à RMSP, o processo de constituição de uma cidade-região aqui descrito e defendido parece estar se configurando com alguma intensidade do ponto de vista populacional. Deve-se 
lembrar, contudo, que o que se vê hoje, ou desde os anos 2000, provavelmente é apenas o prenúncio de um processo que se avoluma e ganhará força nas próximas décadas. Ou seja, o que se pode mostrar com os dados aqui analisados talvez seja apenas o início de uma nova fase do processo de crescimento e expansão do complexo urbano metropolitano expandido do estado de São Paulo.

\section{Considerações finais}

Ao analisar vários autores, como Lencioni (2011b), Diniz e Diniz (2007), entre outros, este trabalho observa que a formação de uma nova morfologia urbana, tal como a cidade-região paulista é um fato notável e prenuncia a constatação elaborada por Borjas e Castells (1997) de que a formação das cidades no mundo contemporâneo seria demarcada por aglomerações do tipo difusas e dispersas, estando assentadas ao longo das grandes vias de transportes, integrando grandes cidades, pequenos municípios, áreas periurbanas, rurais e intersticiais. Além de integrar, nesse conjunto, regiões com distintas funções sendo demarcadas pela intensidade de fluxos de diversos tipos, principalmente os informacionais.

No tocante à integração da região, a mobilidade espacial da população, principalmente os fluxos pendulares, demarcam essa complementaridade regional. Observou-se, através das taxas de crescimento populacional, um crescimento das regiões e dos municípios periféricos em relação à sede regional e das áreas metropolitanas. Os fluxos migratórios mostraram uma complementaridade das regiões metropolitanas elencadas com a RMSP, assim como os fluxos pendulares. Porém, como já reiterado, é preciso salientar que todos esses fluxos estão relacionados com distintas dinâmicas de produção do espaço, mas que integram esse processo de expansão do processo de metropolização.

Como salientado, este estudo não pretende ser conclusivo e muito menos abrangente com relação à discussão sobre a constituição de uma nova forma urbana no estado de São Paulo. Mas, não obstante, procurou-se contribuir para o debate tanto no sentido de corroborar estudos que mostram a configuração de uma nova fase da urbanização paulista, como de defender que a dimensão demográfica é essencial para que se possa apreender cabalmente todo o processo.

Não se têm dúvidas de que foi possível delinear apenas parte da complexidade do fenômeno e, mais que isso, talvez apenas o que seja o seu início. Para as gerações mais antigas que presenciaram, na década de 1970, a construção da rodovia do Bandeirantes - que liga São Paulo a Campinas (hoje já estendida bem mais adiante) - ou viajaram pela rodovia Anchieta que liga a capital a Santos, hoje, ao se depararem com a ampliação de pistas e acessos da primeira e ao experimentarem a moderna rodovia dos Imigrantes que vem para substituir a segunda, talvez consigam imaginar como se modificaram as relações entres essas cidades e suas regiões e o que podemos esperar para o futuro. 


\section{Késia Anastacio Alves da Silva}

Universidade Estadual de Campinas, Instituto de Filosofia e Ciências Humanas, Programa de Pós-Graduação em Demografia. Centro de Estudos da Metrópole/Fundação de Amparo à Pesquisa do Estado de São Paulo. Campinas, SP/Brasil.

kesia.anastacio@nepo.unicamp.br

\section{José Marcos Pinto da Cunha}

Universidade Estadual de Campinas, Instituto de Filosofia e Ciências Humanas, Departamento de Demografia. Núcleo de Estudos de População 'Elza Berquó'. Centro de Estudos da Metrópole/Fundação de Amparo à Pesquisa do Estado de São Paulo. Campinas, SP/Brasil.

zemarcos@nepo.unicamp.br

\section{Guilherme Margarido Ortega}

Universidade Estadual de Campinas, Instituto de Filosofia e Ciências Humanas, Programa de Pós-Graduação em Demografia. Centro de Estudos da Metrópole/Fundação de Amparo à Pesquisa do Estado de São Paulo. Campinas, SP/Brasil.

guilhermeortega@nepo.unicamp.br

\section{Notas}

(*) Este trabalho foi financiado pelo Centro de Estudos da Metrópole (Cebrap, USP), processo no 2013/07616-7, Fundação de Amparo à Pesquisa do Estado de São Paulo (Fapesp). As opiniões, hipóteses e conclusões ou recomendações expressas são de responsabilidade do(s) autor(es) e não necessariamente refletem a visão da Fapesp.

(1) Estudos como de Moura (2009), Lencioni (2011a, 2015), Magalhães (2008), entre outros, tentam compreender a formação de novas formas urbanas no território brasileiro.

(2) Esta relação de complementariedade se perfaz através de dois espectros: o mercado de trabalho e de terras.

(3) As regiões metropolitanas abordadas neste trabalho foram aquelas institucionalizadas até janeiro de 2014. Sendo elas: Região Metropolitana de São Paulo (RMSP), Região Metropolitana de Campinas (RMC), Região Metropolitana da Baixada Santista e Região Metropolitana do Vale do Paraíba e Litoral Norte.

(4) Gottmann em 1961 realizou um estudo sobre o que seriam as megalópoles e suas características.

(5) Estudos como Sassen (2001), Scott et al. (2001), entres outros.

(6) O circuito superior aqui referido faz alusão à teoria dos circuitos da economia urbana de Santos (2005). O autor divide a economia urbana em dois circuitos, assim o circuito superior da economia seria aquele "constituído pelos bancos, comércio e indústria de exportação, indústria moderna, serviços modernos, atacadistas e transportadores". Já o circuito inferior "é constituído essencialmente por formas de fabricação não "capital intensivo", pelos serviços não modernos fornecidos "a varejo" e pelo comércio não moderno e de pequena dimensão. 
(7) Os movimentos pendulares, captados pelos censos demográficos brasileiros mostram os fluxos motivados por estudo ou trabalho entre o município de residência e aquele onde essas atividades são exercidas. Portanto, refletem a concentração desses tipos de atividades em certas espacialidades, o que pode revelar a complementaridade entre aglomerações e/ou municípios da cidade-região.

(8) Os fluxos materiais são aqueles formados pela materialidade, tais como fluxos de mercadoria, pessoas, etc. Já os fluxos imateriais são formados pela imaterialidade e são representados pelos fluxos de informação, etc.

(9) As regiões policêntricas são caracterizadas como a área urbana com uma pluralidade de centros.

(10) Essas condições gerais de produção foram estabelecidas nos tempos pretéritos, destaca-se que este conceito foi desenvolvido por Marx em O Capital. Tais condições vão desde um conjunto de infraestruturas básicas que são imprescindíveis, principalmente para a produção industrial, até o conjunto de regulações trabalhistas, os centros de consumo, bem como as áreas residenciais destinadas aos trabalhadores (Harvey, 1981).

(11) Região metropolitana de São Paulo, região metropolitana de Campinas, região metropolitana do Vale do Paraíba e Litoral Norte, região metropolitana da baixada santista e região metropolitana de Sorocaba.

(12) Aglomeração urbana de Jundiaí e aglomeração urbana de Piracicaba.

(13) Microrregião de Bragantina.

(14) Para maiores detalhes sobre o uso dessa informação, suas potencialidades e limitações consultar: Rigotti, 2011.

(15) Fórmula utilizada para o cálculo: ((Cresc. Abs. Mig./(Ptx+1*Ptx $\left.\left.\left.)^{\wedge}(0,5)\right)\right) / t^{*} 100\right)$.

(16) Os grandes centros, por muito tempo, foram vantajosos para a concentração industrial, mas a elevada concentração passou a gerar custos e desvantagens para a localização de indústrias em certos centros urbanos, principalmente nas grandes metrópoles. Nesse processo de "deseconomia", ocorre a desconcentração industrial.

(17) Neste trabalho, a metrópole até então discutida seria caracterizada pela "grande cidade, que possui funções superiores de comando e gestão e articuladas à economia global, sendo a porta de entrada dos fluxos globais no território nacional, onde se ancoram interesses internacionais e de onde partem, para o território nacional, vetores de modernidade e complexidade". Já a área metropolitana seria a região de influência exercida pela centralidade da metrópole, ou seja, "seria o alcance espacial das atividades de comércio e serviços nela fixados". Por fim, a região metropolitana corresponde à "definição institucional, relacionada aos interesses políticos e, por vezes, motivada pela necessidade de ordenamento do território na escala regional e cuja cidade-polo não é necessariamente uma metrópole" (Firkowski, 2012, p. 37, pp. 23 e 37).

(18) De acordo com Lencioni (2008), a lógica topográfica se refere à lógica dos fluxos materiais e se vincula à distância entre dois pontos. Já a lógica topológica diz respeito aos fluxos imateriais, ou seja, à densidade virtual dos lugares. O estudo da cidade-região sob a hedge dessas duas lógicas se dá pela perspectiva multiescalar, em outras palavras, pela lógica dos diversos fluxos.

(19) Esse fenômeno será analisado mais adiante. 
(20) Pontua-se que algumas das análises realizadas no texto serão feitas apenas para regiões metropolitanas selecionadas. Já que estas se caracterizam como as principais áreas da CR e evidenciam com clareza as relações de complementaridade, através dos fluxos populacionais para a cidade-região. Sendo assim, as RMs analisadas são: RMSP, RMC, RMB, RMVPLN.

(21) Destaca-se que essa premissa é uma hipótese levantada neste trabalho que precisa ser investigada através do perfil daqueles que migram e pendulam no âmbito da cidade-região. Já que a caracterização sociodemográfica e econômica dos fluxos permite elucidar os estruturantes e os condicionantes da formação dessa morfologia.

(22) Esse percentual corresponde à soma de "Município em 2005" e "Outro município", categorias que corresponderiam a áreas situadas fora da região metropolitana de destino.

\section{Referências}

ARAUJO, M., MOURA, R. e DIAS, P. (2011). Cidades médias uma categoria em discussão. In: PEREIRA, R. H. M. e FURTADO, B. A. (orgs.). Dinâmica urbano-regional: rede urbana e suas interfaces. Brasília, Ipea.

ASCHER, F. (1998). Metápolis ou l'avenir dês villes. Paris, Odile Jacob.

BORJA, J. e CASTELLS, M. (1997). Local y global. Barcelona, Taurus.

CANO, W.; BRANDÃO, C. A.; MACIEL, C. S. e MACEDO, F. C. (orgs.) (2007). Economia paulista: dinâmica econômica entre 1980 e 2005. Campinas, Alínea.

CASTELLS, M. (1999). A sociedade em rede. São Paulo, Paz e Terra.

CUNHA, J. M. P da (2003). Redistribuição espacial da população: tendências e trajetória. São Paulo em Perspectiva. São Paulo, Seade, v. 17, n. 3/4, pp. 218-233.

(2011) (org.). Mobilidade espacial da população: desafios teóricos e metodológicos para o seu estudo. Campinas, Núcleo de Estudos de População-Nepo/Unicamp.

(2013). "Dinâmica demográfica e migratória da Região Metropolitana de São Paulo no período 1991-2010: realidades e mitos". In: MARQUES, E. (org.). As transformações de São Paulo nos anos 2000. São Paulo, Editora da Unesp.

(2014). Dinâmica demográfica, migração e projeções populacionais da Macrometrópole Paulista. Relatório de pesquisa de apoio à elaboração do Plano de Ação da Macrometrópole Paulista (PAM). São Paulo, Nepo-Unicamp/Fundap/Emplasa.

(2015). "A migração interna no Brasil nos últimos cinquenta anos: (des)continuidades e rupturas". In: ARRETCHE, M. Trajetórias das desigualdades: como o Brasil mudou nos últimos cinquenta anos. São Paulo, Editora da UNESP/CEM, pp. 279-307.

CUNHA, J. M. P da et al. (2013). Movimentos pendulares na MMP. Relatório de pesquisa de apoio à elaboração do Plano de Ação da Macrometrópole Paulista (PAM). São Paulo, Nepo-Unicamp/ Fundap/Emplasa. 
CUNHA, J. M. P.; SILVA, K. A. A. e ALONSO, R. (2015). Crescimento das cidades médias e interiorização da migração: realidade ou mito? In: IX ENCONTRO NACIONAL SOBRE MIGRAÇÕES. Anais... Campinas. v. 2. pp. 1-22.

DAVIDOVICH, F. (2004). "A 'volta da metrópole' no Brasil: referências para a gestão territorial”. In: RIBEIRO, L. C. de Q. (org.). Metrópoles entre a coesão e a fragmentação, a cooperação e o conflito. São Paulo/Rio de Janeiro, Editora Fundação Perseu Abramo/Fase - Federação de Órgãos para Assistência Social e Educacional.

DE MATTOS, C. (2004). Redes, nodos e cidades: transformação da metrópole latino-americana. In: RIBEIRO, L. C. de Q. (org.). Metrópoles: entre a coesão e a fragmentação, a cooperação e o conflito. São Paulo/Rio de Janeiro, Perseu Abramo/Fase.

DINIZ, C. e DINIZ, B. C. (2007). A região metropolitana de São Paulo: reestruturação, re-espacialização e novas funções. Eure. Santiago (Chile), v. 33, pp. 27-43.

EMPLASA (2012). Macrometrópole Paulista. São Paulo, Emplasa.

FARIA, V. (1991). Cinquenta anos de urbanização no Brasil. Revista Novos Estudos Cebrap. São Paulo, n. 29, pp. 98-119.

FIRKOWSKI, O. L. C. F. e MOURA, R. (2002). Regiões metropolitanas e metrópoles. Reflexões acerca das espacialidades e institucionalidades. RA EGA (UFPR). Curitiba, v. 5, pp. 27-46.

FIRKOWSKI, O. L. C. F. (2012). Porque as regiões metropolitanas no Brasil são regiões, mas não são metropolitanas. Revista Paranaense de Desenvolvimento, v. 122, pp. 19-38.

GARREAU, J. (1991). Edge city: life in the new frontier. Nova York, Doubleday.

GOTTMAN. J. (1961). Megalopolis: The Urbanized Northeastern Seaboard of the United States. Nova York, The Twentieth Century Fund.

HARVEY, D. (1992). Condição pós-moderna. São Paulo, Loyola.

(2013). Os limites do capital. São Paulo, Boitempo.

INDOVINA, F. (1990). La città difusa. Veneza, DAEST-IUAV.

KOWARICK, L. (1982). “A lógica da desordem”. In: CAMARGO, C. P. de (org.). São Paulo 1975. Crescimento e Pobreza. São Paulo, Loyola.

LENCIONI, S. (2003). A emergência de um novo fato urbano de caráter metropolitano em São Paulo. A particularidade de seu conteúdo sócio-espacial, seus limites regionais e sua interpretação teórica. In: ENCONTRO NACIONAL DA ANPUR. Anais...

(2006). “Da Cidade e sua Região à Cidade-região". In: LIMA, L. C.; ELIAS, D. e SILVA, J. B. da (org.). Panorama da Geografia Brasileira I. São Paulo, Annablume.

(2007). Concentração e centralização das atividades urbanas: uma perspectiva multiescalar. Reflexões a partir do caso de São Paulo. Revista de Geografia Norte Grande, v. 1, pp. 1-8.

(2008). Concentração e centralização das atividades urbanas: uma perspectiva multiescalar. Reflexões a partir do caso de São Paulo. Revista de Geografia Norte Grande, n. 29, pp. 7-20.

(2011a). "Transformações socioterritoriais nas metrópoles de Buenos Aires, São Paulo e Santiago". In: LENCIONI, S. e PEREIRA, P. C. X. (orgs.). Transformações socioterritoriais nas metrópoles de Buenos Aires, São Paulo e Santiago. São Paulo, Paim. 
LENCIONI, S. (2011b). A metamorfose de São Paulo: o anúncio de um novo mundo de aglomerações difusas. Revista Paranaense de Desenvolvimento, v. 120, pp. 133-148.

(2015). Urbanização difusa e a constituição de megaregiões: o caso de São Paulo-Rio de Janeiro. Emetropolis: Caderno eletrônico de Estudos Urbanos e Regionais. Rio de Janeiro, n. 22, ano 6.

MAGALHÃES, F. (2008). Transformações socioespaciais na cidade-região em formação: a economia geopolítica do novo arranjo espacial metropolitano. Dissertação de Mestrado. Belo Horizonte, Universidade Federal de Minas Gerais.

MARTINE, G. (1994). A redistribuição espacial da população brasileira durante a década de 80 . Texto para Discussão (Ipea). Rio de Janeiro, pp. 1-46.

MOURA, R. (2009). Arranjos urbano-regionais no Brasil: uma análise com foco em Curitiba. Tese de Doutorado. Curitiba, Universidade Federal do Paraná.

PARR, J. B. (2005). Perspectives on the city-region. Regional Studies. Londres, Routledge, v. 39, n. 5, pp. 555-566.

REIS, N. G. (2006). Notas sobre urbanização dispersa e novas formas de tecido urbano. São Paulo, Via das Artes.

RIGOTTI, J. I. (2011). "Dados censitários e técnicas de análise das migrações no Brasil: avanços e lacunas". In: CUNHA, J. M. P. (org.). Mobilidade espacial da população: desafios teóricos e metodológicos para o seu estudo. Campinas, Nepo/Unicamp.

SANTOS, M. (2005). A urbanização brasileira. São Paulo, Hucitec.

SASSEN, S. (1993). As cidades na economia mundial. São Paulo, Studio Nobel.

(2001). The global city: New York, London, Tokyo. Nova Jersey, Princeton University Press.

SCOTT, A. J. et al. (2001). Cidades-regiões globais. Espaço \& Debates. São Paulo, Neru, v. 17, n. 41, pp. 11-25.

SOJA, E. W. (1994). "O desenvolvimento metropolitano pós-moderno nos EUA: virando Los Angeles pelo avesso". In: SANTOS, M. et al. (org). Território: globalização e fragmentação. São Paulo, Hucitec.

(1996). The third space: journeys to L.A. and other real-and-imaginated places. Oxford, Blackwell.

(2002). Postmetropolis: critical studies of cities and regions. Oxford, Blackwell Publishing.

SPOSITO, E. S. (2007). Reestruturação produtiva e urbana no Estado de São Paulo. Scripta Nova. Barcelona, v. XI, n. 245. Disponível em: http://www.ub.edu/geocrit/sn/sn-24569.htm. Acesso em: 14 set 2014 .

UNFPA (2007). The State of World Population 2007: Unleashing the Potential of Urban Growth. Nova York, UNFP.

Texto recebido em 30/maio/2017

Texto aprovado em 6/set/2017 